\title{
Sociocultural Influences on the Sociopolitical Development of African American Youth
}

\author{
Nkemka Anyiwo, Josefina Bañales, Stephanie J. Rowley, Daphne C. Watkins, and \\ Katie Richards-Schuster \\ University of Michigan
}

ABSTRACT-Sociopolitical development (SPD) is the process by which individuals become aware of social inequality, recognize the status of their social identities, and engage in activism. For racially marginalized youth, race is an important aspect of their SPD. Yet few studies have considered the connections between racial factors and youth's SPD. In this article, we introduce an integrative model situating racial sociocultural processes (i.e., racial identity, racial socialization, and experiences of racial discrimination) within current SPD theory. In particular, we look at African American youth as a case study to discuss how sociocultural factors can contribute to youth's awareness of structures of social inequality (i.e., critical social analysis) and engagement in action against social inequality (i.e., sociopolitical action). We conclude with suggestions for research.

KEYWORDS—social justice; Black youth; sociocultural factors

Nkemka Anyiwo, Josefina Bañales, Stephanie J. Rowley, Daphne C. Watkins, Katie Richards-Schuster, University of Michigan.

The authors thank Matthew Diemer for providing insightful feedback on this article. The research reported is based on work supported by the National Science Foundation Graduate Research Fellowship Program under Grant DGE1256260. Any opinions, findings, and conclusions or recommendations expressed in this material are those of the author(s) and do not necessarily reflect the views of the National Science Foundation. This research was also supported by a Ford Foundation Predoctoral Fellowship.

Correspondence concerning this article should be addressed to Nkemka Anyiwo, School of Social Work, 1080 S. University Avenue, Ann Arbor, MI 48109; e-mail: nanyiwo@umich.edu.

(C) 2018 The Authors

Child Development Perspectives ๑ 2018 The Society for Research in Child Development DOI: $10.1111 /$ cdep.12276
Globally, Black people (i.e., people of African ancestry) experience racial bias rooted in systems of racial oppression (e.g., slavery, apartheid, colonization; 1). Black youth in nations with racial stratification have resisted oppression by engaging in political movements (e.g., South African Students' Movement, Black Lives Matter; 2, 3). However, few studies have examined the factors that promote youth's understanding of oppression and engagement in activism. Sociopolitical development (SPD) theory describes the process by which individuals develop an awareness of and act against sociopolitical factors (i.e., culture, politics, economics) that contribute to inequitable social systems $(4,5)$. Scholars identify racism as influential in the SPD of racially oppressed groups $(5,6)$, yet few studies identify the underlying racial processes that shape youth's SPD. In this article, we propose a framework for contextualizing sociocultural factors in the SPD of Black youth. Although the sociocultural factors we consider (e.g., racial socialization, racial identity, racial discrimination) are likely relevant to the SPD of youth from other backgrounds (e.g., Latinx, Asian, Native American), much of the literature on the sociocultural influences on development is rooted in the experiences of African Americans. Thus, we focus on African American youth as a case study that may apply to other marginalized groups.

We begin with an overview of SPD theory and sociocultural factors that influence African American youth's development. Then we describe connections between these sociocultural factors and aspects of African American youth's SPD, and propose a conceptual model. We conclude with suggestions for research.

\section{SOCIOPOLITICAL DEVELOPMENT}

Paulo Freire's conceptualization of conscientizacao (Portuguese for conscientization) includes the process by which the oppressed and the oppressors develop a critical awareness of social inequity and methods for liberation (7). SPD theory shares theoretical roots with critical consciousness (4), empowerment 
(8), and social justice youth development (9), which incorporate aspects of Freire's notion of conscientizacao. Each of these theories describes how and why individuals develop an awareness of structural oppression and disrupt marginalization. Because SPD theorists often focused on the experiences of African Americans $(5,6)$, we build on this literature to identify the process by which sociocultural factors shape SPD for African American youth.

SPD includes critical social analysis - the ability to analyze the systems that produce inequality —as well as sociopolitical action-behaviors to overturn structural and individual oppression (10). Social analysis is theorized to precede youth's engagement in change, meaning that youth must be conscious about social inequity to engage in sociopolitical action. However, relations between action and analysis might be bidirectional: Engagement in action may also contribute to social analysis.

SPD has implications for psychological development. Although experiences of discrimination can harm development, sociopolitical action can alleviate the impact of racism, increase satisfaction with life, and raise educational attainment among African American youth and young adults (11, 12). Youth's sociopolitical action also has a collective benefit because it can result in community and social change (4). Hence, understanding the factors that facilitate African American youth's SPD is important for facilitating their well-being and addressing the social structures that disrupt their development.

Our model of the sociocultural influences on youth's SPD reflects the notion that SPD is rooted in adolescents' environments (i.e., home, school, community; 5) and is transactional, with interplay between adolescents' characteristics (e.g., features, ideologies) and their sociopolitical engagement. In this way, African American youth's racialized experiences and beliefs contribute to their understanding of social inequality and engagement in action.

\section{SOCIOCULTURAL FACTORS}

We argue that African American youth's sociocultural factors (e.g., experiences with racial discrimination, racial socialization, and racial identity) are integral to their SPD. Issues of race, culture, racial identity, and racial discrimination are likely to be particularly salient during adolescence because youth are actively building identities (13). Adolescents' gains in metacognition, abstract thinking, and social cognition inform their exploration of racial identity and strengthen their ability to identify discrimination on an individual and structural level (14-16). Indeed, African American youth have reported experiencing more types of racial discrimination as they grow older (17). These increases are likely a result of their cognitive gains as well as gains in independence that can raise their susceptibility to racial bias (14). During adolescence, parents more often discuss racial discrimination with their children as well as how to cope with it (14). Thus, adolescents' perceptions of and responses to racial discrimination can be facilitated by their parents' racial socialization messages (15). Taken together, internal and external changes during adolescence can influence the type of racialized experiences African American youth have and how they process them (14).

\section{Racial Discrimination}

A key attribute of SPD is awareness of social inequality (i.e., social analysis; 10). Youth might develop this awareness through direct and vicarious experiences with racial discrimination. In one study of African American, Asian, and Latinx youth (18), adolescents' perceptions of racial discrimination were associated with their consciousness about how racial groups are treated in society. Furthermore, African American college youth's experiences of racial discrimination are related to their beliefs about sociopolitical action (e.g., Black people should fight against injustice and racism) and their engagement in action (19). Beyond direct experiences with racial discrimination, African American youth are also likely to develop skills in social analysis as they witness discrimination experienced by others (20). For example, Trayvon Martin, an African American teenager shot and killed by a neighborhood watchman, became the catalyst for the Black Lives Matter movement, which has increased discussions around race and police brutality (21). Public discourse on the killing of unarmed African Americans has promoted awareness of and activism against racism (1).

Experiencing discrimination does not automatically lead youth to reflect on racial inequality or become engaged in action. Youth might experience discrimination but be unaware of it, or they may interpret discrimination as an individual slight and not a larger systemic issue. However, racial socialization and racial identity may influence youth's understanding of and action against discrimination. Scholars (14) argue that racial identity, racial socialization, and discrimination "are interdependent, cooccurring and, indeed, mutually defining elements of a system of racial knowledge that youth configure, reconfigure, and act upon" (p. 5). Hence, we argue that the interplay among sociocultural factors (i.e., racial discrimination, identity, and socialization) shapes African American youth's ability to analyze inequality (social analysis) and engage in social justice behaviors (sociopolitical action).

\section{Racial Socialization}

Racial socialization is a mechanism by which youth shape their beliefs about their racial group and understand the history and values of that group (14). The two most common forms of racial socialization reported by parents and children are cultural socialization (emphasizing racial/ethnic pride, cultural history, and traditions) and preparation for bias (educating about the reality of racial inequality and preparing youth to respond to discrimination; see 22 for a review). Racial socialization can directly promote youth's positive development and affect the impact of racial discrimination on their developmental outcomes 
(23). Accordingly, we argue that the impact of racial discrimination on African American youth's SPD is likely informed by the messages about race they receive from people they know (e.g., parents) as well as from people distant from them (e.g., public figures).

Cultural socialization that focuses on history and pride may lead to social analysis and sociopolitical action. Parents and schools that convey messages about African American culture can stimulate youth's social analysis (24). Culturally relevant pedagogy, a form of cultural socialization that highlights African Americans' experiences with social inequality, is theorized to facilitate students' SPD (25). Common cultural socialization practices include parents discussing Black history with their children and accompanying their children to Black cultural events. These practices might sensitize Black youth to race or raise their awareness of social movements. Indeed, in a recent study, African American youth who were culturally socialized more than their peers had greater social analysis and, in turn, were more engaged in their communities (i.e., through sociopolitical action; 26).

Messages that prepare youth for bias can make them aware of systemic and individual racial discrimination and guide them on how to respond. These messages may include discussions about youth experiencing racial discrimination or society devaluing Black people. African American youth may use these messages to develop a social analysis that includes an awareness of the structural determinants cause social inequality. Furthermore, youth may receive messages that encourage them to cope with racism through sociopolitical action. For example, African American activists describe how adult caregivers' modeling of community activism when the activists were children promoted their SPD (5). Parents may also communicate the importance of voting or being knowledgeable about current events (i.e., traditional political attitudes and behaviors) to change inequitable social systems (27).

\section{Racial Identity}

Racial identity might also inform African American youth's social analysis and sociopolitical action. Early scholars on Black racial identity conceptualized it as rooted in unique attributes of African American culture and experiences of racial oppression (see 28). The ways that African American adolescents interpret cultural and institutional factors (e.g., racial oppression) can shape their identity development as well as their psychological and behavioral responses (29). Although having a strong cultural connection to one's racial group is a vital component of African Americans' SPD (5), the process by which racial identity contributes to aspects of SPD has neither been identified clearly nor included in models of SPD. One possibility is that African American youth who believe race is central to their self-definition (i.e., have high racial centrality) might be more likely to interpret their experiences through a racial lens. For instance, in one study (30), African American college students with greater racial centrality were more likely to report experiencing racial discrimination.

Racial discrimination and racial socialization can serve as encounters or racial awakenings that trigger African American youth to explore the historical legacy of their racial group, as well as the meaning and significance of their racial identity (1). For example, in a longitudinal study of African American adolescents (31), youth who had experienced discrimination believed more strongly a year later that African Americans are perceived negatively by society. Black adults' experiences of direct or vicarious experiences of racial discrimination, as well as formal and informal education about Black history, have been identified as racial awakenings (1). These racial awakenings may serve as the foundation of social analysis and action. Racial identity can also influence how youth understand and are affected by discrimination. For example, African American youth who believed that others viewed African Americans negatively reported experiencing more racial discrimination, but were also affected less negatively by those experiences (32). These studies suggest that becoming aware of society's views of African Americans might allow youth to identify and cope with experiences of racial discrimination more effectively.

Aspects of racial identity may predict individuals' sociopolitical attitudes (33) and behaviors (26). For instance, African American undergraduates who considered race central to their self-concept and believed African Americans should remain a distinct cultural/political group were less likely to believe that the United States was fair and just (33). In another study (19), dimensions of African American college youth's racial identity predicted their sociopolitical beliefs: Participants for whom race was central to their self-concept and who felt positively about being African American were more likely to engage in sociopolitical action and believe that other African American people should do so.

In summary, we argue that in the context of systematic racism, an interplay among experiences of racial discrimination, racial socialization, and racial identity shapes African American youth's SPD. Experiences of racial discrimination can prompt African American youth to critically analyze social inequality and engage in sociopolitical action. However, their racial identity and exposure to racial socialization messages may influence how they understand racial discrimination and respond to it. African American youth may draw on their racial identity and their experiences of racial socialization to develop a critical social analysis of oppression and engage in sociopolitical action that addresses individual and structural inequality.

\section{CONSIDERATIONS FOR BLACK YOUTH GLOBALLY}

We have contextualized our findings in African American youth's experiences, but sociocultural experiences are likely to influence marginalized youth of other backgrounds and from other nations where racial stratification persists. Black adults in 
nations such as Australia, Bermuda, and South Africa describe racial awakenings similar to Black adults in the United States (1). These awakenings prompted identity development, social analysis, and engagement in activism. In addition, many factors might influence the types of racialized experiences Black youth have and how they understand these experiences. Next, we discuss several examples.

\section{Social Identities and Cultural Variation}

While we have focused on race, it is but one social identity that youth often acquire with other social identities such as gender and sexual orientation (34). SPD is developed when "the individual is able to integrate experience in different power relationships into a multileveled understanding of oppression" (6, p. 258). The extent to which Black youth are privileged and oppressed in dimensions of their identity (e.g., gender, sexual orientation) can shape how they understand racial experiences and other systems of oppression (e.g., sexism, homophobia; 4, 6).

Cultural context might also introduce variation in youth's SPD. In the United States, the sociocultural experiences of Black immigrant youth from the Caribbean and African nations differ from those of African Americans with a generational legacy in the United States (35). For Black immigrant youth, developing a connection to a collective Black identity and becoming acculturated to Black American culture may be important to their SPD. In other nations, Black youth with different sociocultural backgrounds (e.g., ethnicity, country of origin) may differ in SPD.

\section{Cross-Racial Camaraderie and Globalization}

Black youth's ability to recognize similarities in the oppression of other racially marginalized groups may enhance their understanding of systematic racism (26). This awareness might allow them to engage in more sociopolitical action that disrupts racial oppression for all racially marginalized groups (26). Similarly, globalization can contribute to international sociocultural experiences. For example, Black Lives Matter protests have emerged in African and European nations (36). Black youth may be able to examine the sociopolitical forces that affect racially marginalized youth domestically and internationally, and develop camaraderie with other youth.

\section{LOOKING AHEAD}

Investigations of SPD and similar processes (e.g., critical consciousness) explicate the nature of consciousness building and its implications for youth's broader development (e.g., 4). But for racially marginalized youth, scholars should consider the significance of race to their SPD. Our conceptual model starts to identify sociocultural influences (e.g., racial discrimination, racial identity, racial socialization) on African American youth's SPD. However, previous work has found differences in the sociocultural experiences (e.g., racial socialization) of other racially marginalized youth (37). Thus, researchers should examine the unique attributes of the SPD of different racially marginalized youth (e.g., Latinx, Asian, Native American).

We discussed sociocultural factors as predictors of social analysis and sociopolitical action. However, developing a critical awareness about race (38) and engaging in activism can inform the development of racial identity (1). Given that SPD is a transactional process, social analysis and action may inform how youth interpret their experiences of racism and racial socialization. Researchers should examine the interconnections between sociocultural factors and SPD. Scholars can investigate how youth use their racial identity, as well as their experiences of discrimination and racial socialization, to inform their analysis of racial inequality and engagement in activism. Scholars should also examine the relations between the proposed model cross-sectionally and longitudinally to elucidate the directionality between factors.

Our article has implications for scholars and practitioners who investigate the resiliency and healthy psychological development of marginalized youth. A well-established literature has addressed the sociocultural processes that shape marginalized youth's development (see 22, 23), but this work has not contextualized these processes in SPD. Racial identity and racial socialization have been identified as protective factors that allow youth to be resilient amid racial discrimination (23). Examining marginalized youth's SPD gives scholars an opportunity to consider not only how youth are resilient in the presence of structural inequality, but also how they are empowered to actively resist and dismantle systems of oppression that impede their development.

\section{REFERENCES}

1. Neville, H. A., \& Cross, W. E. J. (2017). Racial awakening: Epiphanies and encounters in Black racial identity. Cultural Diversity and Ethnic Minority Psychology, 23, 102-108. https://doi.org/10.1037/ cdp0000105

2. Diseko, N. (1992). The origins and development of the South African Student's Movement (SASM): 1968-1976. Journal of Southern African Studies, 18, 40-62. https://doi.org/10.1080/0305707 9208708305

3. Hope, E. C., Keels, M., \& Durkee, M. I. (2016). Participation in Black lives matter and deferred action for childhood arrivals: Modern activism among Black and Latino college students. Journal of Diversity in Higher Education, 9, 203-215. https://doi.org/10.1037/ dhe0000032

4. Diemer, M. A., Rapa, L. J., Voight, A. M., \& McWhirter, E. H. (2016). Critical consciousness: A developmental approach to addressing marginalization and oppression. Child Development Perspectives, 10, 216-221. https://doi.org/10.1111/cdep.12193

5. Watts, R. J., Williams, N. C., \& Jagers, R. J. (2003). Sociopolitical development. American Journal of Community Psychology, 31, 185-194. https://doi.org/10.1023/A:1023091024140

6. Watts, R. J., Griffith, D. M., \& Abdul-Adil, J. (1999). Sociopolitical development as an antidote for oppression-Theory and action. American Journal of Community Psychology, 27, 255-271. https://d oi.org/10.1023/A:1022839818873 
7. Freire, P. (1993). Pedagogy of the oppressed. New York, NY: Continuum.

8. Christens, B. D., Winn, L. T., \& Duke, A. M. (2016). Empowerment and critical consciousness: A conceptual cross-fertilization. Adolescent Research Review, 1, 15-27. https://doi.org/10.1007/s40894-0150019-3

9. Ginwright, S., \& Cammarota, J. (2002). New terrain in youth development: The promise of a social justice approach. Social Justice, 29, 82-95.

10. Watts, R. J., \& Flanagan, C. (2007). Pushing the envelope on youth civic engagement: A developmental and liberation psychology perspective. Journal of Community Psychology, 35, 779-792. https://d oi.org/10.1002/jcop.20178

11. Chan, W. Y., Ou, S.-R., \& Reynolds, A. J. (2014). Adolescent civic engagement and adult outcomes: An examination among urban racial minorities. Journal of Youth and Adolescence, 43, 1829-1843. https://doi.org/10.1007/s10964-014-0136-5

12. Hope, E. C., \& Spencer, M. B. (2017). Civic engagement as an adaptive coping response to conditions of inequality: An application of phenomenological variant of ecological systems theory (PVEST). In N. J. Cabrera \& B. Leyendecker (Eds.), Handbook on positive development of minority children and youth (pp. 421-435). Cham, Switzerland: Springer International.

13. Erikson, E. H. (1968). Identity: Youth and crisis. New York, NY: Norton.

14. Hughes, D. L., Watford, J. A., \& Del Toro, J. (2016). A transactional/ecological perspective on ethnic-racial identity, socialization, and discrimination. Advances in Child Development and Behavior, 51, 1-41. https://doi.org/10.1016/bs.acdb.2016.05.001

15. Spears Brown, C., \& Bigler, R. S. (2005). Children's perceptions of discrimination: A developmental model. Child Development, 76, 533-553. https://doi.org/10.1111/j.1467-8624.2005.00862.x

16. Umaña-Taylor, A. J., Quintana, S. M., Lee, R. M., Cross, W. E., Rivas-Drake, D., Schwartz, S. J., ... Seaton, E. (2014). Ethnic and racial identity during adolescence and into young adulthood: An integrated conceptualization. Child Development, 85, 21-39. https://doi.org/10.1111/cdev.12196

17. Martin, M. J., McCarthy, B., Conger, R. D., Gibbons, F. X., Simons, R. L., Cutrona, C. E., \& Brody, G. H. (2011). The enduring significance of racism: Discrimination and delinquency among Black American youth. Journal of Research on Adolescence, 21, 662-676. https://doi.org/10.1111/j.1532-7795.2010.00699.x

18. Benner, A. D., \& Graham, S. (2013). The antecedents and consequences of racial/ethnic discrimination during adolescence: Does the source of discrimination matter? Developmental Psychology, 49, 1602-1613. https://doi.org/10.1037/a0030557

19. White-Johnson, R. L. (2012). Prosocial involvement among African American young adults: Considering racial discrimination and racial identity. Journal of Black Psychology, 38, 313-341. https://doi.org/ 10.1177/0095798411420429

20. Hope, E. C., Skoog, A. B., \& Jagers, R. J. (2015). "It'll never be the White kids, it'll always be us": Black high school students' evolving critical analysis of racial discrimination and inequity in schools. Journal of Adolescent Research, 30, 83-112. https://doi.org/10.1177/ 0743558414550688

21. Garza, A. (2016). A herstory of the \#BlackLivesMatter movement. In J. Hobson (Ed.), Are all the women still White: Rethinking race, expanding feminisms (pp. 23-28). Albany, NY: State University of New York Press.
22. Hughes, D., Rodriguez, J., Smith, E. P., Johnson, D. J., Stevenson, H. C., \& Spicer, P. (2006). Parents' ethnic-racial socialization practices: A review of research and directions for future study. Developmental Psychology, 42, 747-770. https://doi.org/10.1037/ 0012-1649.42.5.747

23. Neblett, E. W., Rivas-Drake, D., \& Umaña-Taylor, A. J. (2012). The promise of racial and ethnic protective factors in promoting ethnic minority youth development. Child Development Perspectives, 6, 295-303. https://doi.org/10.1111/j.1750-8606.2012.00239.x

24. Aldana, A., \& Byrd, C. M. (2015). School ethnic-racial socialization: Learning about race and ethnicity among African American students. The Urban Review, 47, 563-576. https://doi.org/10.1007/ s11256-014-0319-0

25. Ladson-Billings, G. (1995). Toward a theory of culturally relevant pedagogy. American Educational Research Journal, 32, 465-491. https://doi.org/10.3102/00028312032003465

26. Lozada, F. T., Jagers, R. J., Smith, C. D., Bañales, J., \& Hope, E. C. (2017). Prosocial behaviors of Black adolescent boys: An application of a sociopolitical development theory. Journal of Black Psychology, 43, 493-516. https://doi.org/10.1177/009579841665 2021

27. Diemer, M. A. (2012). Fostering marginalized youths' political participation: Longitudinal roles of parental political socialization and youth sociopolitical development. American Journal of Community Psychology, 50, 246-256. https://doi.org/10.1007/s10464-0129495-9

28. Sellers, R. M., Smith, M. A., Shelton, J. N., Rowley, S. A., \& Chavous, T. M. (1998). Multidimensional model of racial identity: A reconceptualization of African American racial identity. Personality and Social Psychology Review, 2, 18-39. https://doi.org/10.1207/ s15327957pspr0201_2

29. Spencer, M. B., Dupree, D., \& Hartmann, T. (1997). A phenomenological variant of ecological systems theory (PVEST): A self-organization perspective in context. Development and Psychopathology, 9, 817-833.

30. Sellers, R. M., \& Shelton, J. N. (2003). The role of racial identity in perceived racial discrimination. Journal of Personality and Social Psychology, 84, 1079-1092. https://doi.org/10.1037/0022-3514.84. 5.1079

31. Seaton, E. K., Yip, T., \& Sellers, R. M. (2009). A longitudinal examination of racial identity and racial discrimination among African American adolescents. Child Development, 80, 406-417. https://doi. org/10.1111/j.1467-8624.2009.01268.x

32. Sellers, R. M., Copeland-Linder, N., Martin, P. P., \& Lewis, R. L. (2006). Racial identity matters: The relationship between racial discrimination and psychological functioning in African American adolescents. Journal of Research on Adolescence, 16, 187-216. https://d oi.org/10.1111/j.1532-7795.2006.00128.x

33. Shockley, E., Wynn, A., \& Ashburn-Nardo, L. (2016). Dimensions of Black identity predict system justification. Journal of Black Psychology, 42, 103-113. https://doi.org/10.1177/0095798414557276

34. Shields, S. A. (2008). Gender: An intersectionality perspective. Sex Roles, 59, 301-311. https://doi.org/10.1007/s11199-008-9501-8

35. Thelamour, B., \& Johnson, D. J. (2017). Exploring Black immigrants' and nonimmigrants' understanding of "acting Black" and “acting White." Journal of Black Psychology, 43, 280-304. https://d oi.org/10.1177/0095798416641863

36. Winsor, M. (2016, July 13). Black Lives Matter protests go global, from Ireland to South Africa. ABC News. Retrieved from http:// 
170 | Nkemka Anyiwo et al.

www.abcnews.go.com/International/black-lives-matter-protestsglobal-ireland-south-africa/story?id=40546549

37. Hughes, D., Rivas, D., Foust, M., Hagelskamp, C., Gersick, S., \& Way, N. (2008). How to catch a moonbeam: A mixed-methods approach to understanding ethnic socialization processes in ethnically diverse families. In S. Quintana \& C. McKown (Eds.),
Handbook of race, racism, and the developing child (pp. 226-277). Hoboken, NJ: Wiley.

38. Tatum, B. (1992). Talking about race, learning about racism: The application of racial identity development theory in the classroom. Harvard Educational Review, 62, 1-25. https://doi.org/10.17763/hae r.62.1.146k5v980r703023 